colleagues in the Prison Service. Indeed, if applied to individuals the remarks could even be libellous. To say 'that Prison Medical Officers are in a unique position of diagnosing need and rejecting or selecting for individual services thereby applying the strictures or benefits of society' reads to me as if Medical Officers habitually, customarily or regularly neglect their professional duties in caring for their patients in order to subject them to greater suffering or humiliation. If that is not the authors' intention they should write more carefully. If they meant that, as in the NHS, demands for medical care are greater than resources available and doctors inevitably have to select between patients, then the memorandum should be rewritten to make this clear.

To suggest that the NHS is at this time at least capable of taking over the Prison Medical Service is to lose contact with reality. The NHS cannot cope with the task of its own psychiatric and other services; witness the recurrent scandals and problems partly due to an acute shortage of resources.

The criticism of the Prison Medical Service may reflect more the rejection of the service by the medical establishment than any action of that service. There is no doubt that the Prison Medical Service does not operate in a congenial environment, and many of its facilities are below reasonable standard. Perhaps the College should exert more pressure here, and this will indirectly aid recruiting.

I must ask the College Council to urgently reconsider the College's evidence. I personally repudiate it.

Visiting Psycho-Therapist, David Marjot

H.M. Prison, Wormwood Scrubs

and H.M. Borstals.

\section{THE PRISON MEDICAL SERVICE}

Dear Sir,

I have just read with incredulity and amazement the College's Evidence to the Prison Services Inquiry published in the May issue of the Bulletin. It seems that the document is ill-informed and biased and shows no comprehension of the Prison Medical Officer's unique role in an establishment. Furthermore, the implication comes over strongly that the Prison Medical Officer is in some way inferior and 'bent' by the system. Certainly the Prison Medical Service is a low prestige service on account of its poor working conditions and unattractive patients and therefore has some difficulty in recruiting, but this should not reflect upon the quality of Medical Officers who are appointed.
I comment on the section 'Deficiencies in Existing Prison Medical Services'. The report says that there is a tendency to reject and scapegoat prisoners so that services provided for them are often minimal. Certainly society has rejected them, but part of the Medical Officer's role is to combat that rejection. A prisoner reporting to a doctor is a patient, and is treated courteously and with respect as is any patient. The medical services available are exactly the same as for any other citizen with the exception of a choice of general practitioner. If the College recommendation to have all primary health care of prisoners provided by GPs were implemented the reality of the situation is that the prisoner would still not have the GP of his choice.

Regarding our working environment-yes it is poor and we too have had to work in old buildings and crowded conditions in the same way as our patients for far too long, but doesn't the very fact that we are there protect and safeguard against some of the possible well known effects of overcrowding? The full time Medical Officer is in close touch with staff and inmates whilst being independent of both and so is able to act as friend and confidant to both and mediator on occasions. Part-time Medical Officers are the first to agree that they cannot possibly pick up the atmosphere in the same way because they are not there for much of the day.

Contrary to what the Committee says, Prison Medical Officers are quite free to practise good basic psychiatry, including working with families and following up their patients. However, three factors curtail what we can do-

(a) shortage of auxiliary staff

(b) an administrative system which is unwieldy, poor at communications, and difficult to penetrate and harassment from members of our own profession and our own College who make insinuations of malpractice.

I trust the first two will improve following the Commission's report. The third might improve if colleagues became better informed by visiting us and talking to us about our work before passing judgment. I would welcome a visit from any member of the College Special Committee at any time.

Finally, regarding the Committee's recommendations-

(1) The NHS is floundering-why ask the Prison Medical Service to join a sinking ship!

(2) (a) Many general practitioners already provide primary health care on a part-time basis - they are the first to acknowledge that the presence 
of a full-time officer is also desirable for reasons previously mentioned.

(b) Community Physicians would not be necessary if the problem of old buildings and overcrowding were alleviated.

(c) The present Senior Medical Officer provides the co-ordination of medical services within an institution.

(d) Forensic psychiatrists should have spent at least a few months as full-time Prison Medical Officers before appointment.

(e) Why is it thought that forensic psychiatrists are better able than Prison Medical Officer psychiatrists to write court reports?

(3) Prison Medical Officers are made at present to feel very much the poor relations of the psychiatristwhat NHS grade would we be offered?

(4) We in the Prisons are also pushing all the time for better facilities for the benefit of our patients and staff-a look at the National Health Service does not lead us to believe that we would get them from that direction.

Reform is vital in all areas of the prison system, but it will have to come from within.

R. J. Wool

H. M. Young Offender Centre, Glen Parva,

Leicester.

\section{WHAT'S WRONG WITH PSYCHOGERIATRICS?}

DeAr Sir,

I anticipated that my article in the Bulletin for May 1979 would provoke some adverse response, so I was not surprised by the appearance of Dr Mills' letter in the Bulletin for July.
Perhaps he unwittingly illustrated one of my points about the general unsatisfactoriness of matters psychogeriatric in administrative circles by taking space to point out that (a) the constitution of AACs was immutable, and (b) that there was no College recommendation for a geriatric physician to be on such a Committee - only to add a postscript that I was in fact correct on (b) and might even (subject to a ruling from the Welsh Office) be correct on (a). In any case, why should the 'senior potential colleague' nominated by the Authority not be the local geriatric physician? After all, working with that person will be one of the main tasks of a newly-appointed psychogeriatrician.

If I gave the impression that I was saying that an Assessor's preference of candidates was to be followed, I apologize. What I was attempting to say was that it was within my experience to have my statement rejected when I said that one candidate did possess adequate experience in the psychiatry of old age where others-including the local favourite-though adequately experienced in general psychiatry had little or no knowledge of the subspecialty for which they were being interviewed.

Dr Mills ends with a plea for us to 'struggle on' and make the best of the imperfect world in which we live. We do, constantly. But the Sub-Dean's article in the Bulletin for January 1979 showed that something was seriously wrong in the field of psychogeriatrics, that poor jobs were and still are being produced and advertised. Those of us on the College's panel of Assessors for such posts have known this for some time. Should we really be content to 'struggle on' and not at least discuss the problems?

D. M. D. WhrTE Consultant Psychiatrist

Hereford General Hospital 